the ward, or which bed was his. He insisted he was nine years old and it was impossible to persuade him he had become 10 whilst he was ill. Memory for events before his illness was unimpaired and reading and writing were unaffected. The confusional state cleared and memory for new material gradually improved. Confabulation replaced catastrophic reactions when he was questioned. Confabulation content was fantastic, but compatible with his previous remembered experiences. Inability to remember the names of new nurses was the earliest sign of relapse traced to poor drug compliance and the appearance of new tuberculomata.

Associated behaviour problems were demonstrated on videotape and their management and significance were discussed.

\section{A 19th century description of paroxysmal kinesiogenic choreoathetosis}

Paroxysmal choreoathetosis was described in familial form by Mount and Reack in 1940, ${ }^{1}$ while the kinesinogenic variant of the disease was reported by Kertesz in $1967 .^{2}$ An exhaustive review of the clinical spectrum of paroxysmal motor dyskinesias was made by Lance in $1977 .^{3}$ Current literature agrees that probably the oldest description of paroxysmal choreoathetosis was made by Gower in 1901 as "reflex epilepsy".4

The 19th century physiologist Angelo Mosso (1846-1910) is well known for his studies on muscular fatigue and the mechanical apparatus to measure it (Mosso's ergometer). In 1884, in a book entitled "Fear" dealing with the different motor and autonomic expressions of fear in humans, Mosso wrote "A man in Germany told me some very strange things about his excitability. Amongst others, he said he had to give up dancing because his legs would give way under him at the slightest emotion. Everything made him feel topsyturvy, just offering his arm to a lady to lead her into dinner, or crossing a room full of distinguished people, because the mere idea of being watched would make him shake and stagger about like a drunkard. This disease is known to doctors by the name agoraphobia which means fear of being in public".

The description of these motor abnormalities deserves some comment. In the original Italian "mancar sotto le gambe" (legs giving way) describes a condition of a mixed pattern of inhibition of the muscle tone with involuntary movements, and in a similar way, the terms "tremare e traballare" (to shake and stagger) can be correctly translated in to modern medical language by "choreoathetotic movements".

In a subsequent chapter of the same book, ${ }^{5}$ Mosso discussed the relations between fear and the chorea and ballismus, while in this description no permanent alteration in motricity were noted, implying that the patient's dyskinesias were intermittent and he was able to describe the critical abnormal motor disorder.
Mosso concluded the description by making a diagnosis of agoraphobia, but it is reasonable to consider paroxysmal kinesiogenic choreoathetosis (PKC) an alternative, more probable diagnosis. In fact, the motor disturbances of Mosso's patient showed some peculiar aspects. The first one is that all the hyperkinesiae were triggered by a motor activity, such as, dancing or crossing a room, sometimes performed in a balletic manner (for example, offering support to a partner). The second one is represented by the fact that all abnormal movements were accompanied by embarrassment ("the slightest emotion", being watched by "distinguished people"). Thus Mosso's patient suffered from a disease which was paroxysmal, kinesiogenic, triggered by anxious situations, and expressed itself by conscious choreoathetotic movements, sometimes associated with a lowered antigravitional tone. ${ }^{23}$

It seems possible that, like other motor disorders, ${ }^{67}$ Mosso's description preceded the clinical definition of paroxysmal kinesogenic choreoathetosis.

P MARTINEILI A S GABELLINI Institute of Neurology, Institute of Neurology,
University of Bologna, Bologna, Italy

1 Mount LA, Reack S. Familial paroxysmal choreathetosis in a patient with familial ataxia. Arch Neurol 1940;44:841-6.

1 Kertesz A. Paroxysmal kinesigenic choreathetosis. One entity within the paroxysmal choreathetosis: description of 10 cases including 1 autopsied. Neurology 1967;17:

$680-90$.
Lance JW. Familial paroxysmal dystonic choreathetosis and its differentiation from related syndromes. Ann Neurol its differentiation

4 Gowers WR. Epilepsy and other chronic convulsive diseases: their cause, symptoms and treatment. London: Churchill,
thersich

5 Mosso A. La Paura. Milano: Fratelli Treves Editori. 1884;8:181.

6 Calne DB, Dubini A, Stern G. Did Leonardo describe Parkinson's disease? N Engl J Med 1989;9:594

7 Stern G. Did Parkinsonism occur before 1817? J Neurol Neurosurg Psychiatry 1989 (Special supplement); 11-12. 